\title{
A dip coating process for large area silicon-doped high performance hematite photoanodes
}

\author{
Yelin $\mathrm{Hu},{ }^{1,2}$ Debajeet K. Bora, ${ }^{1,3,4}$ Florent Boudoire, ${ }^{1,3}$ Florian Häussler, ${ }^{5}$ \\ Michael Graetzel, ${ }^{2}$ Edwin C. Constable, ${ }^{3}$ and Artur Braun ${ }^{1, a)}$ \\ ${ }^{1}$ Laboratory for High Performance Ceramics, Empa, Swiss Federal Laboratories for \\ Materials Science and Technology, CH-8600 Dübendorf, Switzerland \\ ${ }^{2}$ Laboratory of Photonics and Interfaces, Institute of Chemical Sciences and Engineering \\ Swiss Federal Institute of Technology, CH-1015 Lausanne, Switzerland \\ ${ }^{3}$ Department of Chemistry, University of Basel, CH-4056 Basel, Switzerland \\ ${ }^{4}$ Advanced Light Source, Lawrence Berkeley National Laboratory, Berkeley, \\ California 94720, USA \\ ${ }^{5}$ Technische Universität Bergakademie Freiberg, D-09596 Freiberg, Germany
}

(Received 3 May 2013; accepted 18 June 2013; published online 18 July 2013)

A facile and low-cost dip-coating process for the deposition of silicon doped hematite films $\left(\mathrm{Si}: \alpha-\mathrm{Fe}_{2} \mathrm{O}_{3}\right.$ ) for hydrogen production by solar water splitting in photo-electrochemical cells (PEC) is presented. The precursors include iron nitrate, oleic acid, tetraethyl orthosilicate (TEOS) and tetrahydrofuran as dispersion agent. Sequential dip coating on transparent conducting oxides glass substrates with heat treatment steps at $500{ }^{\circ} \mathrm{C}$ and $760^{\circ} \mathrm{C}$ yields mesoporous $\mathrm{Si} \alpha-\mathrm{Fe}_{2} \mathrm{O}_{3}$ with a roughness factor of 17 and photocurrent densities $>1 \mathrm{~mA} / \mathrm{cm}^{2}$ at $1.23 \mathrm{~V}$ vs. reversible hydrogen electrode with $\mathrm{SiO}_{\mathrm{x}}$ underlayer and surface modification. A PEC demonstrator with $80 \mathrm{~cm}^{2}$ active area in $1 \mathrm{M}$ potassium hydroxide yields a photocurrent of $35 \mathrm{~mA}$ at $1.5 \mathrm{AM}$ irradiation with the corresponding hydrogen evolution at a Pt wire counter electrode. (C) 2013 AIP Publishing LLC.

[http://dx.doi.org/10.1063/1.4812831]

\section{INTRODUCTION}

Solar hydrogen production in the context of artificial photosynthesis is experiencing a renaissance, with clear goals towards an application and device manufacturing. ${ }^{1,2}$ Hematite $\left(\alpha-\mathrm{Fe}_{2} \mathrm{O}_{3}\right)$ has demonstrated great potential as an oxygen evolving photoanode for hydrogen production by water splitting in photoelectrochemical cells (PEC). This is due to its abundance, stability, and environmental compatibility, as well as suitable band gap and valence band edge position. Despite these attractive characteristics, the efficiency of pure hematite electrode is limited by low rate constant of oxygen evolution, ${ }^{3}$ and short hole diffusion length $(2-4 \mathrm{~nm})^{4}$ as compared to the large light penetration length $\left(\alpha^{-1}=118 \mathrm{~nm}\right.$ at $\left.\lambda=550 \mathrm{~nm}\right){ }^{5}$ Because of this, water oxidation will be caused only by those photo-generated holes which are formed close to the semiconductor-liquid junction (SCLJ), whereas holes created in the bulk will preferentially recombine with electrons before reaching the surface, thus leading to low efficiency in water oxidation. The addition of water oxidation catalysts on the hematite surface has largely overcome the drawback of low oxygen evolution rate constant, such as cobalt ions, ${ }^{6}$ the cobaltphosphate catalyst, ${ }^{7,8}$ and $\mathrm{IrO}_{2}{ }^{9}$ Control of the morphology of nanostructured hematite (nanowires, nanotubes, host-guest ${ }^{10,11}$ ) has proved successful for improving performance by decreasing the distance minority carriers have to travel to reach the reactive surface SCLJ and increasing semiconductor-electrolyte interface areas.

Doping hematite with silicon has been shown to increase its photocurrent density by several orders of magnitude. ${ }^{6,12,13}$ A benchmark for the photocurrent density of water

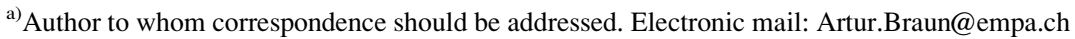


photo-oxidation of silicon-doped $\alpha-\mathrm{Fe}_{2} \mathrm{O}_{3}$ films with dendritic mesostructures has been achieved by atmospheric pressure chemical vapor deposition (APCVD), with efficiency as high as $42 \%$ at $370 \mathrm{~nm}$ and $2.2 \mathrm{~mA} / \mathrm{cm}^{2}$ at $1.23 \mathrm{~V}$ to reversible hydrogen electrode (RHE) in A.M $1.5 \mathrm{G}$ sunlight of $1000 \mathrm{~W} / \mathrm{m}^{2}{ }^{6}$ This remarkable efficiency was attributed to the dendritic mesostructure which shortens the distance photogenerated holes that have to travel to reach SCLJ without loss in light absorption. Although the specific cause of improvement by $\mathrm{Si}$ doping has not been unambiguously determined, it is found that incorporation of silicon leads to disorder in hematite structure $^{14}$ and results in high carrier density and increased hole mobility after doping. ${ }^{15}$ On such Si-doped hematite, it was even possible to detect several different photogenerated hole states with $\mathrm{x}$-ray absorption spectroscopy ${ }^{16,17}$ which virtually matched similar hole states that had been determined with impedance spectroscopy. ${ }^{17-19}$

A renewable and sustainable energy economy will largely require systems, components, and materials, which are based on low-cost and environmental benign precursors and processes that can be scaled up with ease. Recently, Hamd et al. ${ }^{20}$ prepared mesoporous $\alpha-\mathrm{Fe}_{2} \mathrm{O}_{3}$ thin film with a low-cost sol gel method. We report here a facile, low-cost method to fabricate silicon-doped $\alpha-\mathrm{Fe}_{2} \mathrm{O}_{3}$ thin films with good photoelectrochemical water splitting performance. The method allows dip coating of large fluorine-doped tin oxide (FTO) panels and requires neither costly metal organic iron precursors nor costly coating equipment. These films were synthesized following a recently published procedure using iron-oleate precursor combined with the dip-coating approach. ${ }^{21}$ When combined with $\mathrm{SiO}_{\mathrm{x}}$ underlayer from tetraethyl orthosilicate (TEOS) and further surface treated with cobalt-based water oxidation catalysts, our dip-coated hematite displays promising photoelectrochemical performance. We also present a PEC demonstrator with large working electrodes with $10 \times 10 \mathrm{~cm}^{2}$ area prepared by this iron-oleate precursor, which generates oxygen and hydrogen bubbles under bias and illumination at working electrode and counter electrode, respectively.

\section{MATERIALS AND METHODS}

\section{Electrode preparation}

Iron(III) nitrate nonahydrate $\left[\mathrm{Fe}\left(\mathrm{NO}_{3}\right)_{3} \quad 9 \mathrm{H}_{2} \mathrm{O}\right]$ and oleic acid $\left[\mathrm{C}_{18} \mathrm{H}_{34} \mathrm{O}_{2}\right](\geq 99 \%)$ were purchased from Sigma-Aldrich. High pressure liquid chromatograph (HPLC) grade Tetrahydrofuran (THF) was purchased from Alfa Aesar. All reagents were used as-received. The preparation of the hematite film is based on the procedure described recently and here briefly recalled for the reader as shown in Figure $1 .^{21}$ Iron(III) nitrate $(28.0 \mathrm{~g})$ was gradually added to a beaker with oleic acid $(17.0 \mathrm{~g})$ at $120^{\circ} \mathrm{C}$ under consistent stirring to obtain a homogeneous solution. The homogeneous solution was heated at $120^{\circ} \mathrm{C}$ for around $2 \mathrm{~h}$ until no more nitrous gases were evolving from the solution. A reddish brown mass had formed by then, which then cooled down to room temperature and dried for $24 \mathrm{~h}$. It was then mixed with $70 \mathrm{ml}$ of THF and kept in a hood until all product was dissolved, followed by a high speed centrifugation at $4000 \mathrm{rpm}$ for $0.5 \mathrm{~h}$. The supernatant solution was kept in a hood for several hours for evaporation of excess THF until a concentrated iron-oleate precursor was achieved. Certain

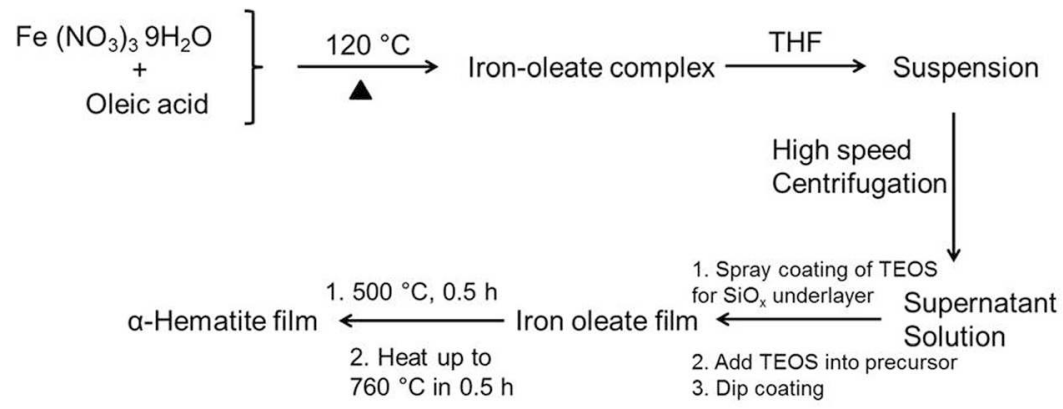

FIG. 1. Scheme of synthesis of Si doping hematite via dip coating. 
amount of TEOS ( 2 mol. \%) was added to the precursor. A FTO aluminoborosilicate glass $(12 \mathrm{~mm} \times 30 \mathrm{~mm} \times 2 \mathrm{~mm}, 10 \Omega / \mathrm{sq}$, SOLARONIX) was pre-treated with $10 \mathrm{mM}$ TEOS/ethanol solution by spraying on a hot plate with temperature of estimated $300^{\circ} \mathrm{C}$. The TEOS coated FTO substrate was then dip-coated (DipMaster ${ }^{\mathrm{TM}}-50$, Chemat Technology Inc., USA). After removal of the precursor solution from the back side of the FTO glass with acetone, it was dried at $75^{\circ} \mathrm{C}$ for $5 \mathrm{~min}$ on a hot plate and then calcined immediately at $500{ }^{\circ} \mathrm{C}$ for $30 \mathrm{~min}$ in air, followed by non-isothermally heating up to $760^{\circ} \mathrm{C}$ within $30 \mathrm{~min}$. After annealing and cooling, excess hematite particles were pealed from the surface and removed. A second layer was then deposited in the same way. For pristine hematite without silicon doping, the precursor was produced in the same way except that no TEOS was added afterwards and the heating procedure was terminated after heating at $500{ }^{\circ} \mathrm{C}$ for $30 \mathrm{~min}$. Dip-coating and annealing were repeated to obtain four layers of undoped pristine hematite, which is known to produce an approximately $600 \mathrm{~nm}$ thick film with optimal photocurrent. ${ }^{22}$

Si-doped hematite photoanodes (coated area of $80 \mathrm{~cm}^{2}$ ) for the hydrogen generator (PEC demonstrator) wee prepared on a $10 \times 10 \mathrm{~cm}^{2}$ FTO aluminoborosilicate glass (Figure 2).

\section{Hydrogen generator (PEC demonstrator)}

To separate and collect the gases generated, a device has been designed and built in our laboratory with a large photoanode (Figure 2). In this hydrogen generator, the photoanode and
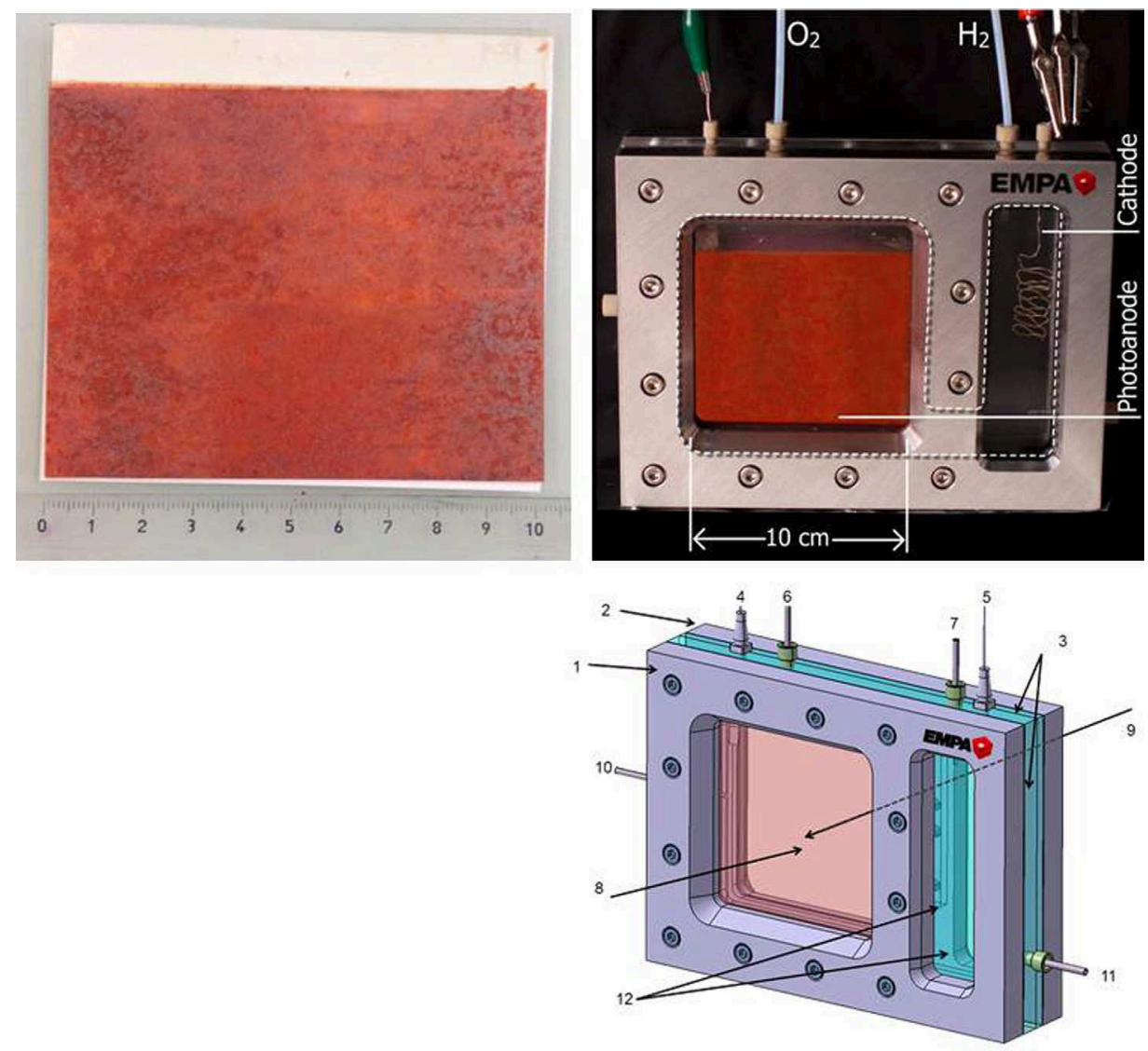

FIG. 2. Left: $10 \mathrm{~cm} \times 10 \mathrm{~cm}$ FTO glass pane coated to with $8 \mathrm{~cm} \times 10 \mathrm{~cm}$ Si-doped hematite. Right: Hydrogen generator with $80 \mathrm{~cm}^{2}$ active area. Bottom: Sketch of the hydrogen generator. 1: Frontplate from steel; 2: Back plate from steel; 3: Plexiglas ${ }^{\circledR}$ frame between front-plate and back-plate; 3: Plexiglas ${ }^{\circledR}$ frame with electrolyte compartment; 4: Electric feedthrough to photoanode; 5: Electric feed-through to cathode wire; 6: Pipe for oxygen outlet; 7: Pipe for hydrogen outlet; 8 Photoanode pane between front plate and Plexiglas ${ }^{\circledR}$ frame; 9: Glass pane or additional photoanode pane between Plexiglas ${ }^{\circledR}$ frame and back plate; 10: Pipe for electrolyte supply; 11: Pipe as electrolyte outlet; 12: Gap in Plexiglas ${ }^{\circledR}$ frame for electrolyte exchange and ionic path. 
the cathode (platinum wire) are located in two adjacent compartments in a Plexiglas ${ }^{\circledR}$ frame. Mixing of the evolving oxygen and hydrogen gas is prevented by a Plexiglas ${ }^{\circledR}$ barrier. Below this mechanical barrier is a $2 \mathrm{~cm}$ wide gap with electrolyte path allowing for ionic conduction. Hydrogen is produced at the cathode, oxygen is produced at the photoanode. Because of this simple design, mixing of the evolving gases in the reactor does not occur and an ion exchange membrane as gas barrier is not necessary.

\section{Scanning electron microscopy and X-ray diffraction analysis}

The morphology of Si-doped and undoped hematite was characterized using a highresolution field emission scanning electron microscope (SEM) (Hitachi S-4800 microscopy). Film cross-section images were from cleaved samples cut by diamond wire saw. The phase composition of the pristine and modified films was examined by powder X-ray diffraction (XRD) analysis (PAN analytical X'Pert PRO, $\mathrm{Cu} \mathrm{K}_{\alpha}$ radiation).

\section{Roughness factor}

The internal surface area of the hematite films compared to their geometric area was determined by adsorption of the azo-dye Orange II (analytical standard, Sigma-Aldrich), as described in Ref. 6. Electrodes with $1.21 \mathrm{~cm}^{2}$ macroscopic surface area were exposed in the dye solution with pH 3.5 for $15 \mathrm{~min}$ (a monolayer could be formed on $\alpha-\mathrm{Fe}_{2} \mathrm{O}_{3}$ in this dye solution with occupied area per dye molecule $0.40 \mathrm{~nm}^{2}$ (Ref. 23) and then put in $0.5 \mathrm{ml}$ of potassium hydroxide $(\mathrm{KOH})(1 \mathrm{M})$ to desorb the adsorbed dye. The concentration of desorbed dye in $\mathrm{KOH}$ solution was determined from the optical density at $446 \mathrm{~nm}$.

\section{Photoelectrochemical characterization}

Photocurrents of the hematite films deposited on the small size $(12 \mathrm{~mm} \times 30 \mathrm{~mm} \times 2 \mathrm{~mm})$ electrodes were measured in a three-electrode configuration photoelectrochemical cell (so-called cappuccino cell of PEEK plastic) with $1 \mathrm{M} \mathrm{KOH}(\mathrm{pH}=13.6)$ as electrolyte $\left(\sim 10 \mathrm{~cm}^{3}\right)$, $\mathrm{Ag} / \mathrm{AgCl} / \mathrm{sat} . \mathrm{KCl}$ as reference, and a platinum sheet $(0.5 \mathrm{~cm} \times 0.5 \mathrm{~cm})$ as counter electrode. The hematite electrode was scanned at $10 \mathrm{mV} / \mathrm{s}$ between -0.3 and $0.8 \mathrm{~V}$ vs. $\mathrm{Ag} / \mathrm{AgCl}$. The potential of the working electrode was controlled by a Voltalab80 PGZ 402 potentiostat and converted to the RHE by the equation $E_{R H E}=E_{A g / A g C l}+0.197 \mathrm{~V}+0.059 \mathrm{pH}$ (at $25^{\circ} \mathrm{C}$ ). The film was illuminated through the electrolyte and a fused silica window with a $0.52 \mathrm{~cm}^{2}$ aperture. The light source was an 1.5 AM solar simulator (HAL 302 Solar Simulator, 350-750 nm, Asahi Spectra, Japan) by removing infrared $(>720 \mathrm{~nm})$ and short UV light $(<320 \mathrm{~nm})$ with a filter.

The photocurrent action spectra were obtained under light from a $300 \mathrm{~W}$ Xe lamp with an integrated parabolic reflector (Ceramx PE 300 BUX) and the light passed through a monochromator (Bausch \& Lomb, bandwidth $10 \mathrm{~nm}$ ). The wavelength was scanned at the rate of $5 \mathrm{~nm} / \mathrm{s}$ from 650 to $300 \mathrm{~nm}$. The monochromatic photocurrent of the $\mathrm{Fe}_{2} \mathrm{O}_{3}$ electrode was corrected by subtracting dark current from light current of hematite films and compared with that of a UV enhanced/Si-photodiode (Oriel 71883) of known incident photon to current efficiency (IPCE) spectrum.

The photocurrent of $\mathrm{Si}$ doped hematite films deposited on the large area panes $(10 \mathrm{~cm}$ $\times 10 \mathrm{~cm}$ ) was measured in the hydrogen generator (two-electrode system with) $1 \mathrm{M} \mathrm{KOH}$ $(\mathrm{pH}=13.6)$ as electrolyte, and a platinum wire as counter electrode, under illumination by two Halogen headlights (HL 400, $500 \mathrm{~W}$ ). The potential was controlled by a G-Serie potentiostat (Gamry Instruments/C3 Prozess- und Analysentechnik GmbH).

\section{RESULTS AND DISCUSSION}

The morphology and the cross-section of silicon-doped hematite ( 2 mol. \% doping) are shown in Figure 3. The cross-section of the silicon-doped film (Figure 3(a)) shows a $265 \mathrm{~nm}$ thick mesoporous $\alpha-\mathrm{Fe}_{2} \mathrm{O}_{3}$ film grown on the $\mathrm{SnO}_{2}: \mathrm{F}$ substrate layer with 2-layer dip coating approach. The rough $\mathrm{Si}$ doped hematite film consists of agglomerated nanoparticles with a 

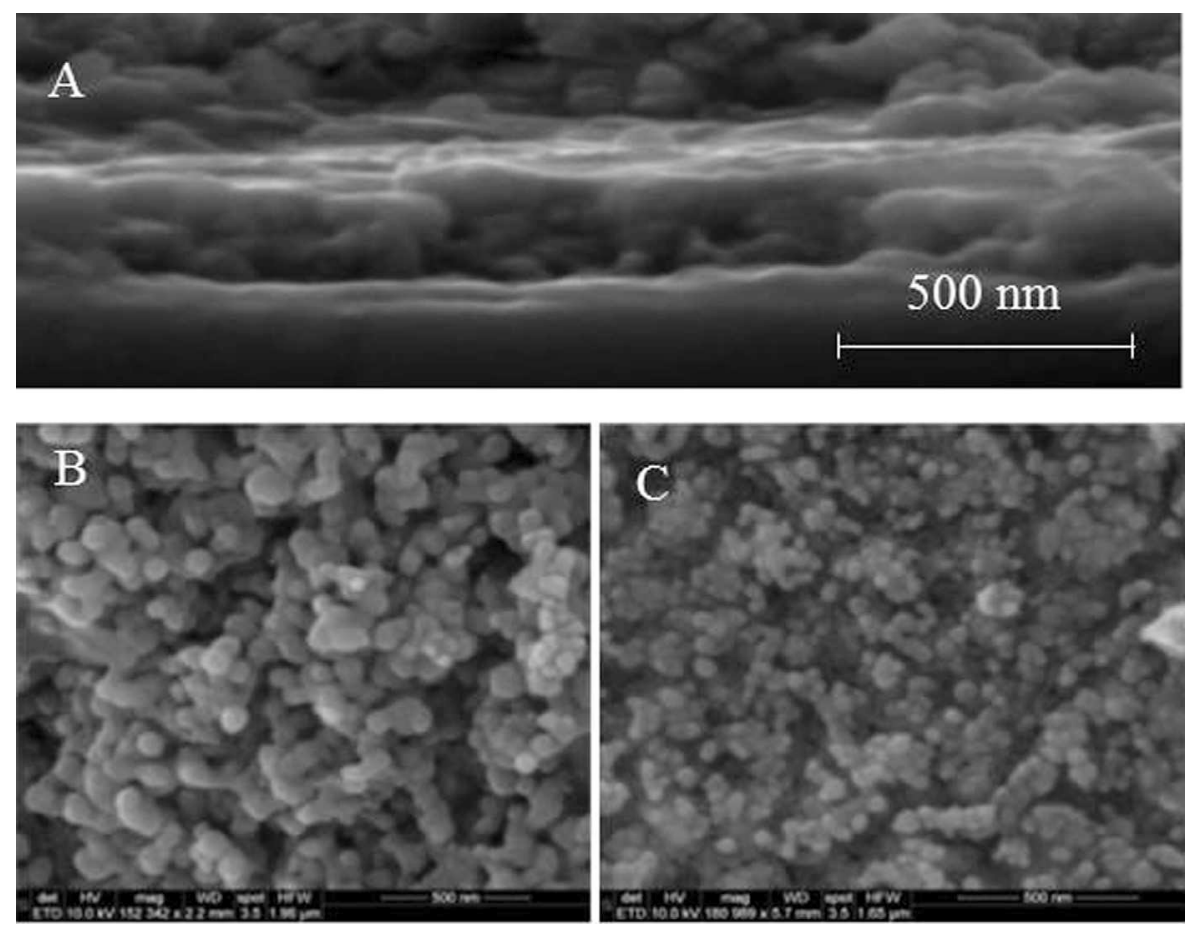

FIG. 3. SEM images of $\mathrm{Fe}_{2} \mathrm{O}_{3}$ films (2 wt. \%) prepared by iron oleate precursor on FTO conducting glass. (a) Cross-section of $265 \mathrm{~nm}$ thick mesoporous Si-doped $\mathrm{Fe}_{2} \mathrm{O}_{3}$ on FTO. (b) Top view of an undoped pristine $\mathrm{Fe}_{2} \mathrm{O}_{3}$ film. (c) Top view of the Si-doped $\mathrm{Fe}_{2} \mathrm{O}_{3}$ film.

diameter between 50 and $74 \mathrm{~nm}$ (Figure 3(c)), while in the undoped pristine hematite sample the particle size is slightly larger with $72-140 \mathrm{~nm}$ (Figure 3(b)). The internal surface area of the hematite films as compared to the projected surface area is determined by dye adsorption (Dye Orange II) on five samples, and the $\mathrm{RF}=17 \pm 0.8$.

Powder X-ray diffraction pattern of silicon-doped hematite film in Figure 4 shows mainly diffraction peaks from $\mathrm{SnO}_{2}$ layer of FTO glass substrate (cassiterite, blue lines). Two strong peaks due to $\alpha-\mathrm{Fe}_{2} \mathrm{O}_{3}$ (hematite), that is, the (104) and (110) reflection (in hexagonal coordinates), were shown in Figure 4, with much weaker peaks corresponding to the (012), (113), (024), (116), (018), (214), (300), and (1010) planes. The photocatalytic activity of a crystallite depends on the chemical reactivity of particular facet, namely (110) plane for hematite. ${ }^{24}$ Comparing the (104) and (110) peaks, it is found that the (104) diffracted peak is higher than (110), and an even higher ratio of (104)/(110) peaks could be found when temperature is lower than $760^{\circ} \mathrm{C}$, accompanying with poor photoelectrochemical activity. ${ }^{25}$

Figure 5 shows the current-voltage $(I-V)$ curve of an undoped pristine hematite and silicondoped hematite electrodes with a series of Si-doping level in dark and in simulated sunlight under the conditions classically used in the literature $(1 \mathrm{M} \mathrm{KOH}$ aqueous solution, $\mathrm{pH}$ 13.6). The undoped pristine hematite was prepared at temperatures $500{ }^{\circ} \mathrm{C}$ with four subsequent dipcoating and annealing steps with an FTO glass substrate, which is known to produce the optimum photocurrent density. ${ }^{22}$ The dark current of the pristine hematite is negligible within the measurement potential range. Under illumination water oxidation photocurrent onsets at 1.05 $\mathrm{V}_{\mathrm{RHE}}$ and the current density then increases rapidly, gaining photocurrent values of up to $0.25 \mathrm{~mA} / \mathrm{cm}^{2}$ and $0.6 \mathrm{~mA} / \mathrm{cm}^{2}$ at $1.23 \mathrm{~V}_{\mathrm{RHE}}$ and $1.6 \mathrm{~V}_{\mathrm{RHE}}$, respectively (The photocurrent onset potential is defined according to Ref. 26: the place where line tangent to the inflection point of the photocurrent rise intersects the dark current is determined as the onset potential.) This result is impressive since the photocurrent of APCVD hematite sample without silicon doping is in the order of $10 \mu \mathrm{A} / \mathrm{cm}^{2}$ at $1.23 \mathrm{~V}_{\mathrm{RHE}},{ }^{6}$ and sol-gel hematite samples with $0.25 \mathrm{~mA} / \mathrm{cm}^{2}$ 


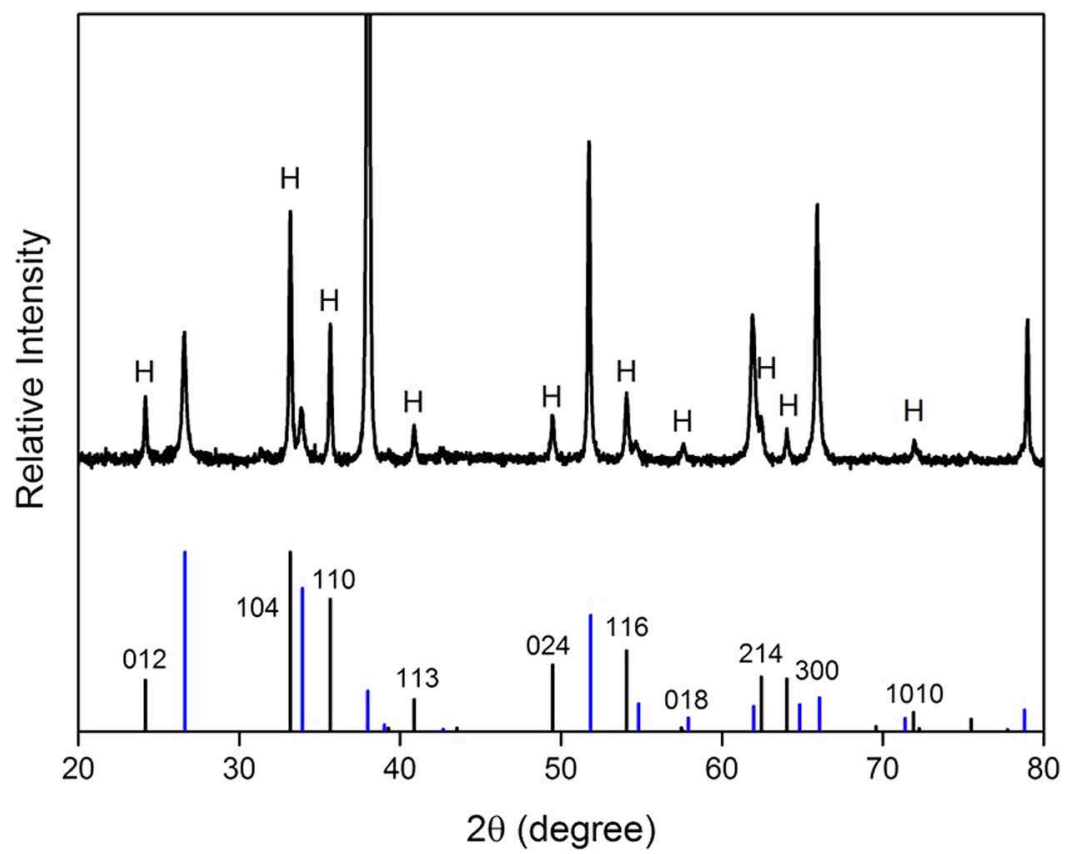

FIG. 4. X-ray diffraction pattern of Si-doped $\mathrm{Fe}_{2} \mathrm{O}_{3}$ film on $\mathrm{SnO}_{2}$ (hematite peaks marked with $\mathrm{H}$ ). The standard powder pattern of hematite is showed in black lines with plane indices in hexagonal coordinates and of $\mathrm{SnO}_{2}$ (cassiterite) is presented in blue lines.

photocurrent at $1.23 \mathrm{~V}_{\mathrm{RHE}}$ need to be treated at temperature up to $750{ }^{\circ} \mathrm{C}^{20}$ This would be explained by possible carbon residues in the film as electron donors from iron oleate precursor. ${ }^{6}$

The silicon-doped hematite samples were prepared at temperature of $500^{\circ} \mathrm{C}$ for $30 \mathrm{~min}$ first, then followed by an isothermal heating up to $760^{\circ} \mathrm{C}$ in $30 \mathrm{~min}$. Two subsequent dipcoating and annealing steps were needed for optimal photocurrent, which is different from four

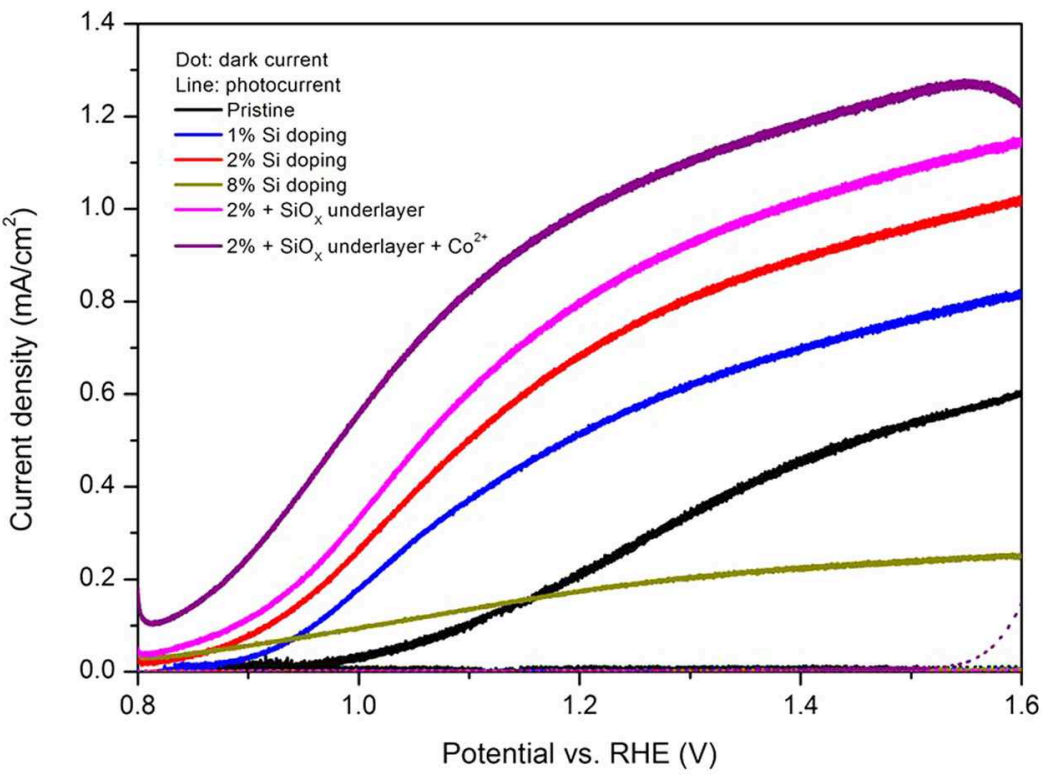

FIG. 5. Current-voltage characteristics in dark and under simulated sunlight at a scan rate of $10 \mathrm{mV} / \mathrm{s}$. Dotted line is dark current density and solid line is calculated photocurrent density. 
steps for pristine hematite. Samples were prepared on FTO aluminoborosilicate glass which can stands high temperature and will not melt during synthesis. For the silicon-doped hematite samples, the onset potentials of hematite samples were cathodically shifted after silicon doping to low potential value of $0.91 \mathrm{~V}_{\mathrm{RHE}}, 0.88 \mathrm{~V}_{\mathrm{RHE}}$, and lower than $0.8 \mathrm{~V}_{\mathrm{RHE}}$ for $1 \mathrm{~mol} . \%, 2 \mathrm{~mol} \%$, and $8 \mathrm{~mol} . \%$ doping level, respectively. The photocurrent density was improved after incorporation of $1 \mathrm{~mol} . \%$ silicon dopant into hematite, and achieved $0.55 \mathrm{~mA} / \mathrm{cm}^{2}$ and $0.81 \mathrm{~mA} / \mathrm{cm}^{2}$ at $1.23 \mathrm{~V}_{\mathrm{RHE}}$ and $1.6 \mathrm{~V}_{\mathrm{RHE}}$, respectively. The performance was further improved by increasing doping level to $2 \mathrm{~mol} . \%$ and the photocurrent density was further enhanced up to $0.72 \mathrm{~mA} / \mathrm{cm}^{2}$ and $1.02 \mathrm{~mA} / \mathrm{cm}^{2}$ at $1.23 \mathrm{~V}_{\mathrm{RHE}}$ and $1.6 \mathrm{~V}_{\mathrm{RHE}}$, respectively. Further increasing of doping level up to $8 \mathrm{~mol} . \%$, however, significantly suppressed the performance of hematite samples, which could be explained by enhanced recombination from overdoping. The values of $2 \mathrm{~mol}$. \% Sidoped hematite are superior to that of the control sample as well as to those of Si-doped samples with other doping level over the full bias range. The improvement of photocurrent density after silicon doping is consistent with the photocurrent action spectra. The IPCE of the hematite electrode without $\mathrm{SiO}_{\mathrm{X}}$ underlayer was measured and shown as a function of wavelength in Figure 6. The silicon doping enhances the IPCE over a factor of 3 between 300 and $500 \mathrm{~nm}$.

The Si-doped hematite films exhibit only then a high photocurrent density when they have been annealed at a significantly high temperature than necessary for the growth of pristine hematite films. Then, they show similar morphology like the films shown in Refs. 20 and 27. This is explained in Ref. 27 that $\mathrm{Sn}^{4+}$ ions will migrate from the FTO substrate to $\alpha-\mathrm{Fe}_{2} \mathrm{O}_{3}$ film during elevated sintering temperature and act as electron donating impurities to enhance the electronic conductivity. A peak between 487 and $495 \mathrm{eV}$ attributed to the $4 \mathrm{~d}$ and $3 \mathrm{~d}$ binding energies of $\mathrm{Sn}$ is displayed in the $\mathrm{X}$-ray photoelectron spectrum of $\mathrm{Si}$ doped hematite sample.

Thin insulating layers of $\mathrm{SiO}_{2}$ are widely used in metal-insulator-semiconductor devices and can sufficiently improve the photoelectrochemical performance of hematite. ${ }^{28}$ There it was speculated that hematite films grown on a $\mathrm{SiO}_{2}$ modified substrate would fully cover the substrate, whereas those grown on bare FTO substrate would form islands, leading to different crystalline organization which can be critical for photoactivity of hematite films. ${ }^{28}$ The difference in nucleation and growth process is commonly explained by a difference in interfacial strain due to crystal lattice mismatch between hematite/ $/ \mathrm{SiO}_{2}$ and hematite/ $/ \mathrm{SnO}_{2} .{ }^{29}$ The $\mathrm{SiO}_{2}$ underlayer forms a semiconductor heterostructure with the iron oxide layer with a possibly

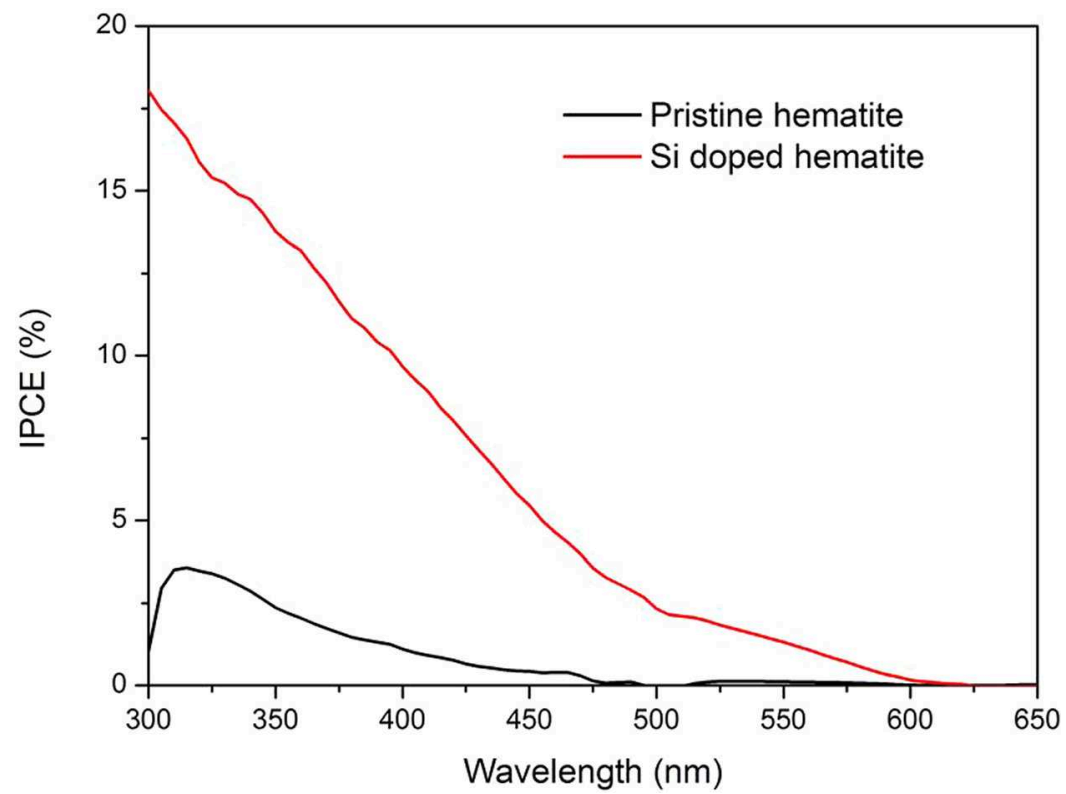

FIG. 6. IPCE spectrum of the same electrode as in Figure 3 at $1.23 \mathrm{~V}_{\text {RHE }}$. Silicon doped hematite sample was without $\mathrm{SiO}_{\mathrm{x}}$ underlayer and $\mathrm{Co}^{2+}$ surface modification. 


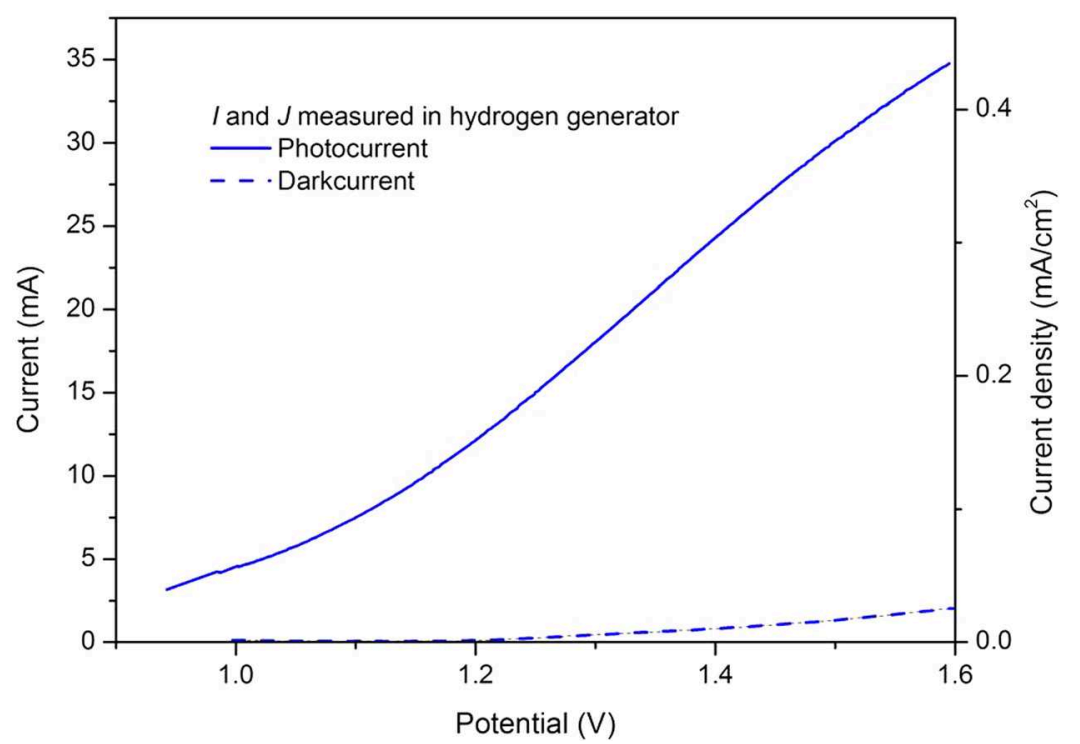

FIG. 7. Photocurrent measured in our group on hematite film sample with area of $100 \mathrm{~cm}^{2}$ working area by an up-scaled solar simulator.

improved energy level alignment at the interface. ${ }^{6}$ For our studies, the $\mathrm{SiO}_{2}$ underlayer clearly improved the photocurrent of $\mathrm{Si}$ doped samples (Figure 5); the photocurrent density at 1.23 $\mathrm{V}_{\mathrm{RHE}}$ and $1.6 \mathrm{~V}_{\mathrm{RHE}}$ achieved $0.83 \mathrm{~mA} / \mathrm{cm}^{2}$ and $1.13 \mathrm{~mA} / \mathrm{cm}^{2}$ with a similar onset potential as the sample without $\mathrm{SiO}_{2}$ underlayer.

After photoelectrochemical characterization the Si-doped electrode $(2 \mathrm{~mol} . \%)$ of Figure 5 was rinsed with distilled water, and then treated with several drops of $10 \mathrm{mM} \mathrm{Co}\left(\mathrm{NO}_{3}\right)_{2}$ aqueous solution after drying. The PEC response of this $\mathrm{Co}^{2+}$ surface-decorated photoelectrode was measured again and is also shown in Figure 3. The dark current is negligible up to $1.52 \mathrm{~V}_{\mathrm{RHE}}$, above which it rises steeply. The cobalt treatment results in a $60 \mathrm{mV}$ cathodic shift and the photocurrent at $1.23 \mathrm{~V}_{\mathrm{RHE}}$ increases to $1.03 \mathrm{~mA} / \mathrm{cm}^{2}$. Interestingly, the photocurrent density achieves its maximum at $1.55 \mathrm{~V}_{\mathrm{RHE}}$ and it decreases afterward, which is due to the subtraction of dark current from light current.

The photocurrent measured with the hydrogen generator is reaching $33 \mathrm{~mA}$ at $1.6 \mathrm{~V}$, which corresponds to a photocurrent density of $0.41 \mathrm{~mA} / \mathrm{cm}^{2}$ (Figure 7). This photocurrent density is around half of the value obtained with a small $0.52 \mathrm{~cm}^{2}$ working photoanode $\left(1.02 \mathrm{~mA} / \mathrm{cm}^{2}\right.$ at 1.6 $\left.\mathrm{V}_{\mathrm{RHE}}\right)$. This current loss can be caused by a longer electrolyte ionic path, in the case of the hydrogen generator, leading to an increased resistivity of the system. ${ }^{30,31}$ The current loss could also be caused by the inefficient surface area of counter electrode, which, ideally, should be at least two times larger than the working electrode area. ${ }^{31}$ Another reason for the current loss is inhomogeneous current distribution at the working electrode, possibly resulting from inhomogeneous potential distribution or potential gradient along the films. Nevertheless the $33 \mathrm{~mA}$ obtained with the generator at $1.6 \mathrm{~V}$ allowed a hydrogen production of $5 \mathrm{ml}$ per hour. It is therefore possible to upscale and integrate our Si-doped hematite photoanodes into a hydrogen production device.

\section{CONCLUSION}

Thin films of silicon-doped hematite $\left(\alpha-\mathrm{Fe}_{2} \mathrm{O}_{3}\right)$ were prepared via a facile and costeffective iron oleate complex and their performance as photoanodes for water oxidation was characterized. Iron oleate precursor was first prepared by iron nitrate, oleic acid, and TEOS, and $\alpha-\mathrm{Fe}_{2} \mathrm{O}_{3}$ mesoporous films were fabricated by dip-coating approach, followed by annealing at $500{ }^{\circ} \mathrm{C}$ and isothermal heating up to $760^{\circ} \mathrm{C}$. Real surface area determination by dye adsorption yields a roughness factor of 17. For comparison, $\mathrm{Fe}_{2} \mathrm{O}_{3}$ prepared from colloidal solutions 
had a roughness factor of $30,{ }^{32}$ and hematite prepared from APCVD had a roughness factor of $21{ }^{6}$ Under illumination in $1 \mathrm{M} \mathrm{KOH}$, high photocurrent density values $\left(1.03 \mathrm{~mA} / \mathrm{cm}^{2}\right)$ are obtained at $1.23 \mathrm{~V}_{\mathrm{RHE}}$ with TEOS underlayer and after surface treatment with Cobalt ion catalyst. A demonstrator with this new photoanode material deposited on large area working electrode $\left(10 \times 10 \mathrm{~cm}^{2}\right)$ was also reported in this work, displaying the generation of hydrogen and oxygen during working operation.

\section{ACKNOWLEDGMENTS}

Financial support from the Swiss National Science Foundation (Project Nos. 132126, 137868, and R'Equip 206021-121306), and from the Swiss Federal Office of Energy (Project Nos. BFE \#152316-101883 and \#153613-102809) is gratefully acknowledged. We wish to thank Mr. HansJürgen Schindler (EMPA) and Maurin Cornuz (EPFL) for XRD measurement and IPCE measurement, respectively.

${ }^{1}$ J. J. Concepcion, R. L. House, J. M. Papanikolas, and T. J. Meyer, Proc. Natl. Acad. Sci. USA 109(39), 15560 (2012).

${ }^{2}$ A. Thapper, S. Styring, G. Saracco, A. W. Rutherford, B. Robert, A. Magnuson, W. Lubitz, A. Llobet, P. Kurz, A. Holzwarth, S. Fiechter, H. de Groot, S. Campagna, A. Braun, H. Bercegol, and V. Artero, Green 3(1), 43 (2013).

${ }^{3}$ M. P. Dare-Edwards, J. B. Goodenough, A. Hamnett, and P. R. Trevellick, J. Chem. Soc., Faraday Trans. I 79, 2027 (1983).

${ }^{4}$ J. H. Kennedy and K. W. Frese, J. Electrochem. Soc. 125, 709 (1978).

${ }^{5}$ I. Balberg and H. L. Pinch, J. Magn. Magn. Mater. 7, 12 (1978).

${ }^{6}$ A. Kay, I. Cesar, and M. Graetzel, J. Am. Chem. Soc. 128, 15714 (2006).

${ }^{7}$ D. K. Zhong, M. Cornuz, K. Sivula, M. Graetzel, and D. R. Gamelin, Energy Environ. Sci. 4, 1759 (2011).

${ }^{8}$ R. Saito, Y. Miseki, and K. Sayama, Chem. Commun. 48, 3833 (2012).

${ }^{9}$ S. D. Tilley, M. Cornuz, K. Sivula, and M. Gratzel, Angew. Chem., Int. Ed. 49, 6405 (2010).

${ }^{10}$ M. Stefik, M. Cornuz, N. Mathews, T. Hisatomi, S. Mhaisalkar, and M. Gratzel, Nano Lett. 12, 5431 (2012).

${ }^{11}$ S. C. Riha, M. J. D. Vermeer, M. J. Pellin, J. T. Hupp, and A. B. F. Martinson, ACS Appl. Mater. Interfaces 5, 360 (2013).

${ }^{12}$ J. H. Kennedy, R. Shinar, and J. P. Ziegler, J. Electrochem. Soc. 127, 2307 (1980).

${ }^{13}$ R. Shinar and J. H. Kennedy, Sol. Energy Mater. 6, 323 (1982).

${ }^{14}$ J. A. Glasscock, P. R. F. Barnes, I. C. Plumb, and N. Savvides, J. Phys. Chem. C 111, 16477 (2007).

${ }^{15}$ L. Peilin and E. A. Carter, J. Appl. Phys. 112, 013701 (13 pp.) (2012).

${ }^{16}$ A. Braun, K. Sivula, D. K. Bora, J. F. Zhu, L. Zhang, M. Grätzel, J. H. Guo, and E. C. Constable, J. Phys. Chem. C 116, $16870(2012)$

${ }^{17}$ D. K. Bora, Y. Hu, S. Thiess, S. Erat, X. Feng, S. Mukherjee, G. Fortunato, N. Gaillard, R. Toth, K. Gajda-Schrantz, W. Drube, M. Grätzel, J. Guo, J. Zhu, E. C. Constable, D. D. Sarma, H. Wang, and A. Braun, "Between Photocatalysis and Photosynthesis: Synchrotron spectroscopy methods on molecules and materials for solar hydrogen generation," J. Electron Spectrosc. Relat. Phenom. (in press).

${ }^{18}$ B. Klahr, S. Gimenez, F. Fabregat-Santiago, T. Hamann, and J. Bisquert, J. Am. Chem. Soc. 134, 4294 (2012).

${ }^{19}$ L. Bertoluzzi and J. Bisquert, J. Phys. Chem. Lett. 3, 2517 (2012).

${ }^{20}$ W. Hamd et al., Phys. Chem. Chem. Phys. 14, 13224 (2012).

${ }^{21}$ D. K. Bora, A. Braun, S. Erat, O. Safonova, T. Graule, and E. C. Constable, Curr. Appl. Phys. 12, 817 (2012).

${ }^{22}$ D. K. Bora et al., J. Phys. Chem. C 115, 5619 (2011).

${ }^{23}$ S. Takeda, M. Fukawa, Y. Hayashi, and K. Matsumoto, Thin Solid Films 339, 220 (1999).

${ }^{24}$ O. Warschkow, D. E. Ellis, J. Hwang, N. Mansourian-Hadavi, and T. O. Mason, J. Am. Ceram. Soc. 85, 213-220 (2002).

${ }^{25}$ D. K. Bora, Ph.D. thesis \# 9782, Universität Basel, 2012.

${ }^{26}$ F. Le Formal, N. Tetreault, M. Cornuz, T. Moehl, M. Grätzel, and K. Sivula, Chem. Sci. 2, 737 (2011).

${ }^{27}$ K. Sivula, R. Zboril, F. Le Formal, R. Robert, A. Weidenkaff, J. Tucek, J. Frydrych, and M. Gratzel, J. Am. Chem. Soc. 132, 7436 (2010).

${ }^{28}$ F. Le Formal, M. Grätzel, and K. Sivula, Adv. Funct. Mater. 20, 1099 (2010).

${ }^{29}$ J. A. Venables, G. D. T. Spiller, and M. Hanbucken, Rep. Prog. Phys. 47, 399 (1984).

${ }^{30}$ L. Andrade, T. Lopes, H. A. Ribeiro, and A. Mendes, Int. J. Hydrogen Energy 36, 175 (2011).

${ }^{31}$ R. van de Krol and M. Grätzel, Photoelectrochemical Hydrogen Production (Springer, US, 2012).

${ }^{32}$ U. Bjorksten, J. Moser, and M. Gratzel, Chem. Mater. 6, 858 (1994). 